The Journal of

Thoracic and

Cardiovascular

Surgery

Vol 124, No. 2, August 2002

\title{
Oxygenated multidose delivery of crystalloid esmolol cardioplegia as an alternative to high potassium cardioplegia
}

James D. McCully, MD

See related article on page 340 .

From the Division of Cardiothoracic Surgery, Beth Israel Deaconess Medical Center, Harvard Institutes of Medicine, Boston, Mass.

Received for publication Oct 22, 2001; accepted for publication Oct 31, 2001.

Address for reprints: James D. McCully, $\mathrm{MD}$, the Division of Cardiothoracic Surgery, Beth Israel Deaconess Medical Center, Harvard Institutes of Medicine, 77 Avenue Louis Pasteur, Room 144, Boston, MA 02115 .

J Thorac Cardiovasc Surg 2002;124:219-20

Copyright $(\subset) 2002$ by The American Association for Thoracic Surgery

0022-5223/2002 $\$ 35.00+0 \quad \mathbf{1 2 / 1 / 1 2 1 7 6 2}$

doi:10.1067/mtc.2002.121762

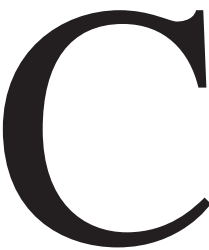

ardioplegia is used as a myoprotective agent for the alleviation of surgically induced ischemic injury, incurred during cardiac operative procedures, to allow the functional preservation of the myocardium. These solutions allow for the rapid electromechanical arrest of the myocardium through alteration of cellular electrochemical gradients. ${ }^{1}$ Most cardioplegic solutions use a high potassium content to arrest the heart. ${ }^{2}$ The use of hypothermic potassium cardioplegia in adult cardiac surgery increases the safely available intraoperative time and has been correlated with improved postischemic myocardial functional recovery and reduced postoperative mortality. ${ }^{3}$

Potassium-induced arrest maintains the heart in a depolarized state, significantly decreasing the energy demand of the myocardium, but basal metabolic energy requirements are sustained and thus still constitute a significant energy expenditure. ${ }^{4}$ The advantages of cardioplegic arrest in providing a bloodless field are tempered by the fact that depolarization also leads to the alteration of ion flux across the sarcolemmal membrane and is associated with both increased cytosolic calcium accumulation and the significant depletion of cellular high-energy (adenosine triphosphate) reserves. ${ }^{5-9}$

The use of blood cardioplegia is currently the criterion standard with which all cardioplegic formulations must be compared, and its benefits relative to crystalloid cardioplegia have been extensively reported. ${ }^{10-13}$ Similarly, the relative contributions of hypothermia (cold, warm, and tepid cardioplegia) and the route of administration of cardioplegia (retrograde, antegrade, and combined retrograde and antegrade delivery) have been examined. ${ }^{14-18}$ The applicability of high-potassium cardioplegia to the neonatal and immature heart remains poorly defined and will not be addressed here, but the reader is directed to reviews by del Nido ${ }^{19}$ and Hammon ${ }^{20}$ and the recent reviews of Allen and colleagues ${ }^{21}$ and Ihnken ${ }^{22}$ for further information.

Despite continuous improvements in surgical technique and cardioplegic formulations, the inadequacies of current intraoperative myocardial protection protocols and formulations, most of which maintain as their basis high-potassium depolarizing arrest, remain a concern. Novel myoprotective protocols to allow enhanced functional recovery of the myocardium after ischemia and reperfusion continue to be needed. In this issue of the Journal, Bessho and Chambers ${ }^{23}$ present evidence in favor of the use of oxygenated multidose crystalloid esmolol cardioplegia to induce cardiac arrest as an alternative to St Thomas' Hospital cardioplegic solution No. 2.

Esmolol is an ultra-short acting (9-minute half-life) cardioselective $\beta$-blocker that is rapidly hydrolyzed by an esterase in the blood cell cytosol to an inactive form, thus avoiding the negative inotropic and chronotropic effects of prolonged $\beta$-block-

The Journal of Thoracic and Cardiovascular Surgery • Volume 124, Number 2219 
ade. Bessho and Chambers ${ }^{23}$ present a well-designed set of studies with appropriate controls to investigate the role of oxygenation of crystalloid esmolol cardioplegia and the effects of single and multidose delivery in providing enhanced cardioprotection in an isolated buffer-perfused rat heart model of global ischemia and reperfusion. Comparisons with deoxygenated control solutions and with $\mathrm{St}$ Thomas' Hospital cardioplegic solution No. 2 are provided. Bessho and Chambers ${ }^{23}$ also investigate the efficacy of oxygenated multidose crystalloid esmolol cardioplegia in providing cardioprotection after $60,75,90$, and 120 minutes of global ischemia and 60 minutes of reperfusion.

Intrinsic to the development of new myoprotective protocols for use in cardiac surgery is the requirement that these protocols be as good as or better than traditional cardioplegia in providing enhanced postischemic functional recovery and myocellular preservation. In their article, Bessho and Chambers ${ }^{23}$ show that the oxygenation of multidose crystalloid esmolol cardioplegia is essential to provide effective cardioprotection. They further show that multidose crystalloid esmolol cardioplegia must be delivered at a constant pressure $(45 \mathrm{~mm} \mathrm{Hg}$ ) rather than a constant flow. They show-as evidenced by recovery of left ventricular developed pressure, left ventricular end-diastolic pressure, coronary flow, and heart rate- that delivery of oxygenated multidose crystalloid esmolol cardioplegia at a constant pressure provides complete myocardial protection for as long as 90 minutes at $37^{\circ} \mathrm{C}$ and is superior to St Thomas' Hospital cardioplegic solution No. 2.

The short half-life of esmolol ( 9 minutes) necessitates 3 minutes of infusion every 15 minutes at a constant pressure of $45 \mathrm{~mm} \mathrm{Hg}$ to maintain pharmacologic effectiveness, however; this protocol is not significantly different from current cardioplegic readministration protocols for intermittent cardioplegia and provides for rapid cardiac arrest similar to traditional cardioplegia. Bessho and Chambers ${ }^{32}$ speculate that the effects of esmolol cardioplegia include enhanced balance of myocardial oxygen supply and demand through the reduction of inotropic and chronotropic actions and may be associated with increased blood flow to ischemic areas or the redistribution of blood flow from the subepicardium to the subendocardium. They concede that further studies with a larger animal model are needed for determination of surgical relevance, as is investigation of delivery routes, temperature, and applicability to neonatal, immature, and aged patients. The current inability to deliver esmolol in blood cardioplegia because of inactivation also requires further study.

In this issue of the Journal, Bessho and Chambers ${ }^{23}$ present a well-designed study that closely examines a surgically relevant issue in an experimental model. Although the cardioprotective mechanisms remain to be elucidated, the benefits of esmolol cardioplegia offer the potential to provide a needed alternative to traditional high-potassium depolarizing cardioplegia.

\section{References}

1. Wright R, Levitsky S, Rao K, Holland C, Feinberg H. Potassium cardioplegia. Arch Surg. 1978;113:976-80.

2. Shiroshi MS. Myocardial protection- the rebirth of potassium based cardioplegia. Texas Heart Inst J. 1999;26:71-86.

3. Hearse DJ. Cardioplegia: the protection of the myocardium during open heart surgery: a review. J Physiol (Paris). 1980;76:751-68.

4. Sternbergh WC, Brunsting LA, Abd-Elfattah AS, Wechsler AS. Basal metabolic energy requirements of polarized and depolarized arrest in rat heart. Am J Physiol. 1989;256(3 Pt 2):H846-51.

5. Hearse DJ, Garlick PB, Humphrey SM. Ischemic contracture of the myocardium: mechanism and prevention. Am J Cardiol. 1977;39:98693.

6. McCully JD, Tsukube T, Ataka K, Krukenkamp IB, Feinberg H, Levitsky S. Myocardial cytosolic calcium accumulation during ischemia/reperfusion: the effects of aging and cardioplegia. J Cardiothorac Surg. 1994;9:449-52.

7. Tsukube T, McCully JD, Faulk E, Federman M, LoCicero J, Krukenkamp IB, et al. Magnesium cardioplegia reduces cytosolic and nuclear calcium and DNA fragmentation in the senescent myocardium. Ann Thorac Surg. 1994;58:1005-11.

8. Tsukube T, McCully JD, Federman M, Krukenkamp IB, Levitsky S. Developmental differences in cytosolic calcium accumulation associated with surgically induced global ischemia: optimization of cardioplegic protection and mechanism of action. $J$ Thorac Cardiovasc Surg. 1996;112:175-84.

9. Tsukube T, McCully JD, Metz RM, Cook CU, Levitsky S. Amelioration of ischemic calcium overload correlates with high-energy phosphates in the senescent myocardium. Am J Physiol. 1997;42(1 Pt 2):H418-27

10. Follette D, Fey K, Becker H, Foglia R, Steed D, Mulder DG, et al. Superiority of blood cardioplegia over asanguinous cardioplegia-an experimental and clinical study. Chir Forum Exp Klin Forsch. 1980: 279-83.

11. Vinten-Johansen J, Thourani VH. Myocardial protection: an overview. J Extra Corpor Technol. 2000;31:38-48.

12. Schlensak C, Doenst T, Beyerdorf F. Clinical experience with blood cardioplegia. Thorac Cardiovasc Surg. 1998;46 Suppl 2:282-5.

13. Finney RS, Gardner TJ. Myocardial protection after 15 years of cardioplegia. Curr Opin Cardiol. 1990;5:226-34.

14. Conti VR, Bertranou EG, Blackstone EH, Kirklin JW, Digerness SB. Cold cardioplegic versus hypothermia for myocardial protection: randomized clinical study. J Thorac Cardiovasc Surg. 1978;76:577-89.

15. Cohen G, Borger MA, Weisel RD, Rao V. Intraoperative myocardial protection: current trends and future perspectives. Ann Thorac Surg. 1999;65:1995-2001.

16. Ruengsakulrach P, Buxton BF. Anatomic and hemodynamic considerations influencing the efficiency of retrograde cardioplegia. Ann Thorac Surg. 2001;71:1389-95.

17. Caldarone CA, Krukenkamp IB, Misare BD, Levitsky S. Perfusion deficits with retrograde warm blood cardioplegia. Ann Thorac Surg. 1994;57:403-6.

18. Misare BD, Krukenkamp IB, Lazer ZP, Levitsky S. Retrograde is superior to antegrade continuous warm blood cardioplegia for acute cardiac ischemia. Circulation. 1992;86(Suppl):II-393-7.

19. del Nido PJ. Myocardial protection and cardiopulmonary bypass in neonates and infants. Ann Thorac Surg. 1997;643:878-9.

20. Hammon JW. Myocardial protection in the immature heart. Ann Thorac Surg. 1995;60:839-42.

21. Allen BS, Barth MJ, Ilbawi MN. Pediatric myocardial protection: an overview. Semin Thorac Cardiovasc Surg. 2001;13:56-72.

22. Ihnken K. Myocardial protection in hypoxic immature hearts. Thorac Cardiovasc Surg. 2000;48:46-54.

23. Bessho R, Chambers DJ. Myocardial protection with oxygenated esmolol cardioplegia during prolonged normothermic ischemia in the rat. J Thorac Cardiovasc Surg. 2002;124:340-51. 